\title{
Publisher Correction to: Injective Hulls of Quantale-Enriched Multicategories
}

\author{
Eros Martinelli ${ }^{1}$ \\ Published online: 23 July 2021 \\ (c) Springer Nature B.V. 2021
}

\section{Correction to: Applied Categorical Structures https://doi.org/10.1007/s10485-021-09650-0}

Unfortunately, in the original publication of the article, an author contribution section was included which is not related to the article. The original article has been corrected.

Publisher's Note Springer Nature remains neutral with regard to jurisdictional claims in published maps and institutional affiliations.

The original article can be found online at https://doi.org/10.1007/s10485-021-09650-0.

Eros Martinelli

eros.martinelli@ua.pt

1 Department of Mathematics, Center for Research and Development in Mathematics and Applications, University of Aveiro, Aveiro, Portugal 